\title{
DETERMINATION OF OPTIMAL BALL BURNISHING PARAMETERS FOR SURFACE ROUGHNESS OF ALUMINUM ALLOY
}

\author{
D.B. Patel ${ }^{1}$ and T.M. Patel ${ }^{2}$ \\ Mechanical Eng. Department, LDRP-ITR, Gandhinagar, India. \\ E-mail: tushar.modasa@gmail.com
}

\begin{abstract}
Burnishing is a cold-working process, which easily produces a smooth and workhardened surface through the plastic deformation of surface irregularities. In the present work, the influences of the main burnishing parameters (speed, feed, force, number of tool passes, and ball diameter) on the surface roughness are studied. It is found that the burnishing forces and the number of tool passes are the parameters that have the greatest effect on the workpiece surface during the burnishing process.
\end{abstract}

Keywords: Burnishing process; surface roughness; number of burnishing tool passes; Taguchi method.

\section{INTRODUCTION}

Many finishing processes can be used to produce surfaces with high-quality textures. These processes could be classified as chip removal processes such as grinding, and chip-less processes such as burnishing (Hassan, Al-Jalil \& Ebied, 1998; Sagbas \& Kahrama, 2009; Singh, 2011, 2012; Mohamed \& Khan, 2012; Najiha, Rahman, Yusoff, \& Kadirgama, 2012). Burnishing processes have many advantages over chip removal processes (Chen \& Shiou, 2003). Burnishing increases the surface hardness of the workpiece, which in turn, improves wear resistance (Hassan \& Al-Bsharat, 1996a,b), increases corrosion resistance (Hassan \& Al-Bsharat, 1996b; Hassan \& Maqableh, 2000; Khan, Rahman, Kadirgama, Maleque, \& Ishak, 2011), improves tensile strength (Hassan \& Al-Bsharat, 1996b), maintains dimensional stability, and improves the fatigue strength by inducing residual compressive stresses in the surface of the workpiece (Hassan \& Al-Bsharat, 1996a,b; Hassan, 1997).
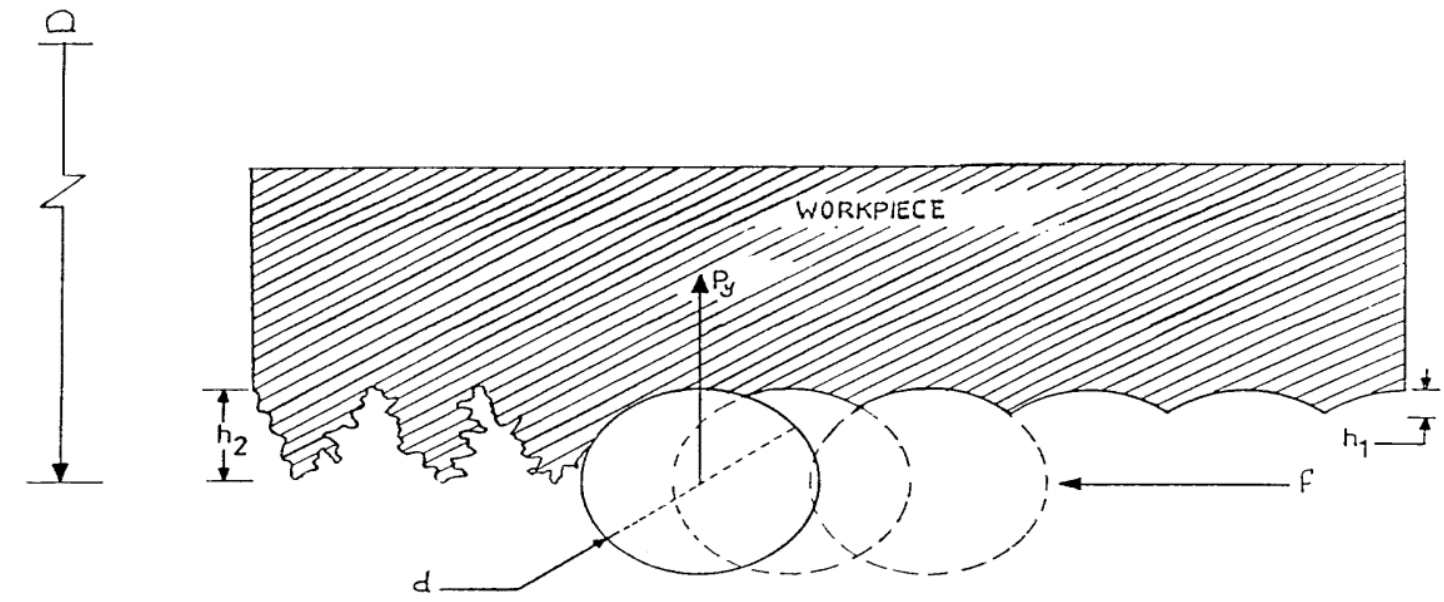

Figure 1. Burnishing process (Hassan, 1997). 
The process of burnishing is performed simply by applying a highly polished and hardened ball or roller, subject to external forces, to the surface of flat or cylindrical workpieces, as shown in Figure 1. The ball or roller is fed in an appropriate direction according to the workpiece surface. This causes the peaks of the metallic surface to spread out permanently, when the applied burnishing pressure exceeds the yield strength of the metallic material, filling the valleys and thus, some form of smoothing takes place (El-Axir, Othman, \& Abodiena, 2008a,b). In the experiments described below, cylindrical turned non-ferrous workpieces were used. The workpieces were held in the center of a lathe and a ball-tool was applied to burnish the surfaces of the workpieces. Burnishing experiments were carried out using different burnishing forces $(P)$, feeds $(J)$, speeds $(V)$, and number of tool passes $(N)$ (Hassan \& Al-Bsharat, 1996a). Commercially available cylindrical aluminum was used as the workpiece material. The influence of the above-mentioned parameters on the surface roughness of the non-ferrous workpieces was studied. No lubricant was used during any of the experiments described in this paper.

\section{EXPERIMENTAL DETAILS}

\section{Test Equipment}

Experiments were conducted on a Y2K lathe. A simple tool was designed and constructed to carry out the experimental work. Hardened alloy steel balls were used. The balls used had a Rockwell hardness of HRC80 and average arithmetical surface roughness $\left(R_{a}\right)$ of $0.01 \mu \mathrm{m}$. The ball holder was supported elastically by a pre-calibrated spring, which could apply the required force when pressed onto the workpiece surface. The use of the spring was important for reducing sticking due to friction between the ball and the workpiece. When the ball was pressed against the surface of the workpiece, the spring supporting the ball would be compressed. The amount of spring compression with relation to the applied vertical force $\left(P_{y}\right)$ was calibrated. Only the effect of the vertical force was studied, as the effects of other forces were negligible.

\section{Test Materials}

The workpieces were received as cylindrical bars of 40-mm diameter. The bars were cut to appropriate lengths $(200-250 \mathrm{~mm})$ and turned to a diameter of $38 \mathrm{~mm}$. Each workpiece was divided into 15 regions, each of $30 \mathrm{~mm}$, according to the parameters to be studied. It was not possible to obtain the chemical compositions of the non-ferrous metals, as a spectrographic analyzer was not available.

\section{Roughness Measurements}

The surface roughness $\left(R_{a}\right)$ was measured using a MITUTOYO SJ-201 surface roughness instrument.

\section{Experimental Methods}

Experiments were planned according to Taguchi's L25 orthogonal array, which has 25 rows corresponding to the number of tests with 5 columns at 5 levels, as shown in Table 
1. This orthogonal array is chosen because of its capability of checking the interactions among the factors.

Table 1. Factors and their levels.

\begin{tabular}{|c|c|c|c|c|c|}
\hline Factors & Level 1 & Level 2 & Level 3 & Level 4 & Level 5 \\
\hline Speed (RPM) & 45 & 75 & 120 & 190 & 300 \\
\hline Feed $(\mathrm{mm} / \mathrm{rev})$ & 0.068 & 0.085 & 0.1 & 0.154 & 0.205 \\
\hline Force (kgf) & 5 & 10 & 15 & 20 & 25 \\
\hline $\begin{array}{l}\text { No. of tool } \\
\text { passes }\end{array}$ & 1 & 2 & 3 & 4 & 5 \\
\hline
\end{tabular}

The experimental results were transferred to a signal-to-noise $(\mathrm{S} / \mathrm{N})$ ratio. There are three categories of quality characteristic in the analysis of the $\mathrm{S} / \mathrm{N}$ ratio: (i) thelower-the-better, (ii) the-higher-the-better, and (iii) the-nominal-the-better. Regardless of the category of the quality characteristic, process parameter settings with the highest $\mathrm{S} / \mathrm{N}$ ratio always yielded the optimum quality with minimum variance. The-lower-thebetter category was used to calculate the $\mathrm{S} / \mathrm{N}$ ratio for both quality characteristics of surface roughness and workpiece surface temperature, according to Eq. (1)

$$
\eta=-10 \log _{10}\left(\frac{1}{n} \sum_{i=0}^{n} \mathrm{y}_{\mathrm{i}}^{2}\right),
$$

where:

$\eta=$ Signal-to-noise ratio

$\mathrm{n}=$ Number of repetitions of experiment

$y_{i}=$ Measured value of quality characteristic

\section{RESULTS AND DISCUSSION}

The roughness of the burnished aluminum was measured at each specified region with the help of the MITUTOYO SJ-32 surface roughness tester, and the average values of several measurements were reported for each region.

\section{Effect of Cutting Speed}

The investigation into the effect of burnishing speed, during the ball-burnishing process of aluminum, found that initially, when the speed was increased, the roughness of the aluminum decreased up to a burnishing speed of $120 \mathrm{rpm}$. Then, with a further increase in speed above $120 \mathrm{rpm}$, the surface roughness increased. The increase occurs when factors such as possible chattering of the ball-burnishing tool and the increase in temperature, which increases the possibility of material transformation between the burnishing ball and workpiece interface, start to have a decisive effect.

\section{Effect of Burnishing Feed}

Figures 2 and 3 show that the surface roughness decreased with an increase in feed rate up to $0.85 \mathrm{~mm} / \mathrm{rev}$, beyond which is started to increase under the given working conditions. When feed rate is low, the distance between successive traces is small. As 
the ball passes along the work piece, it will cause a repeated deformation action on the surface. When the feed rate is high, the distance between successive burnishing traces is large, which causes less of an improvement in the surface finish of the workpiece.

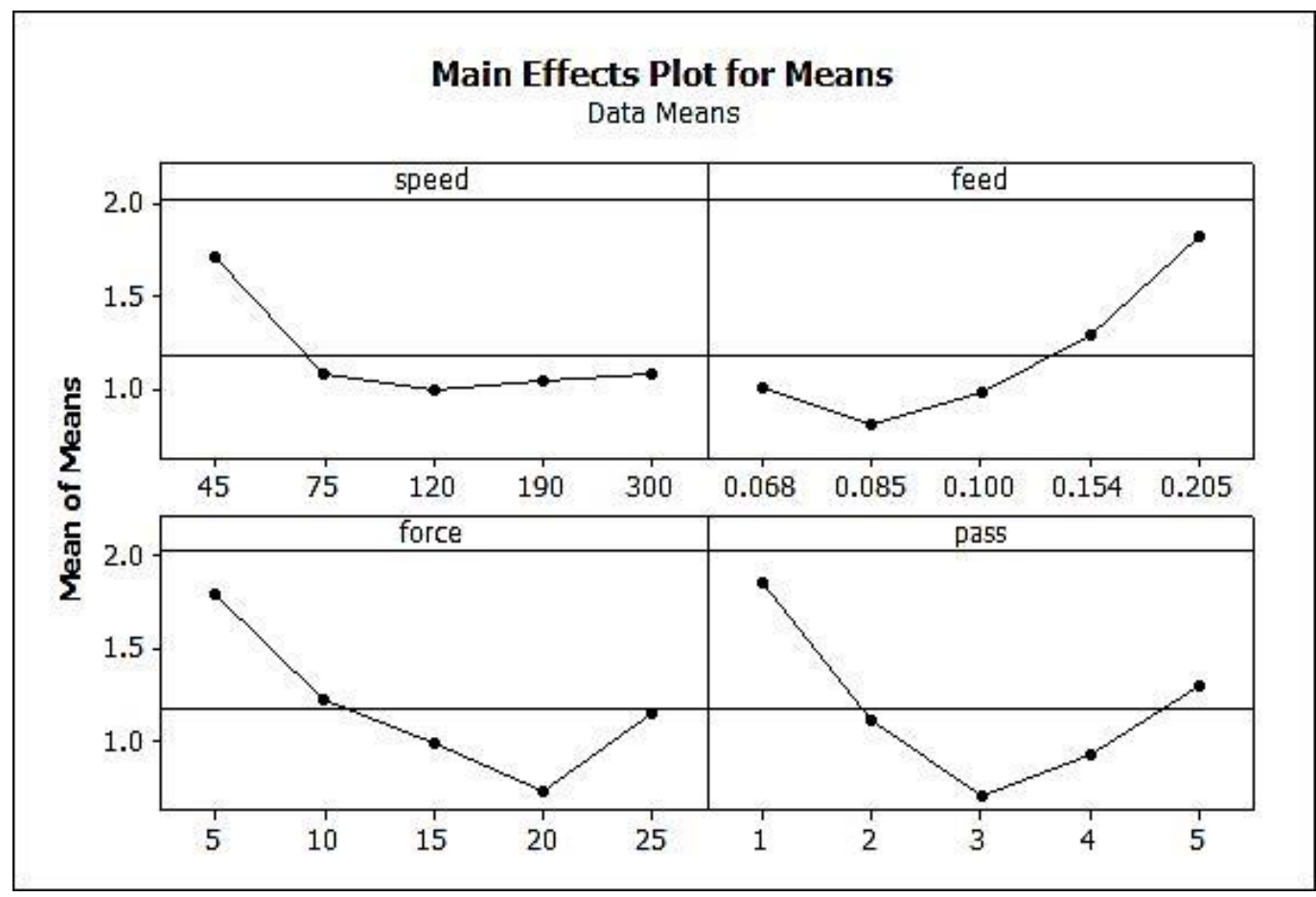

Figure 2. Main effect plot for means.

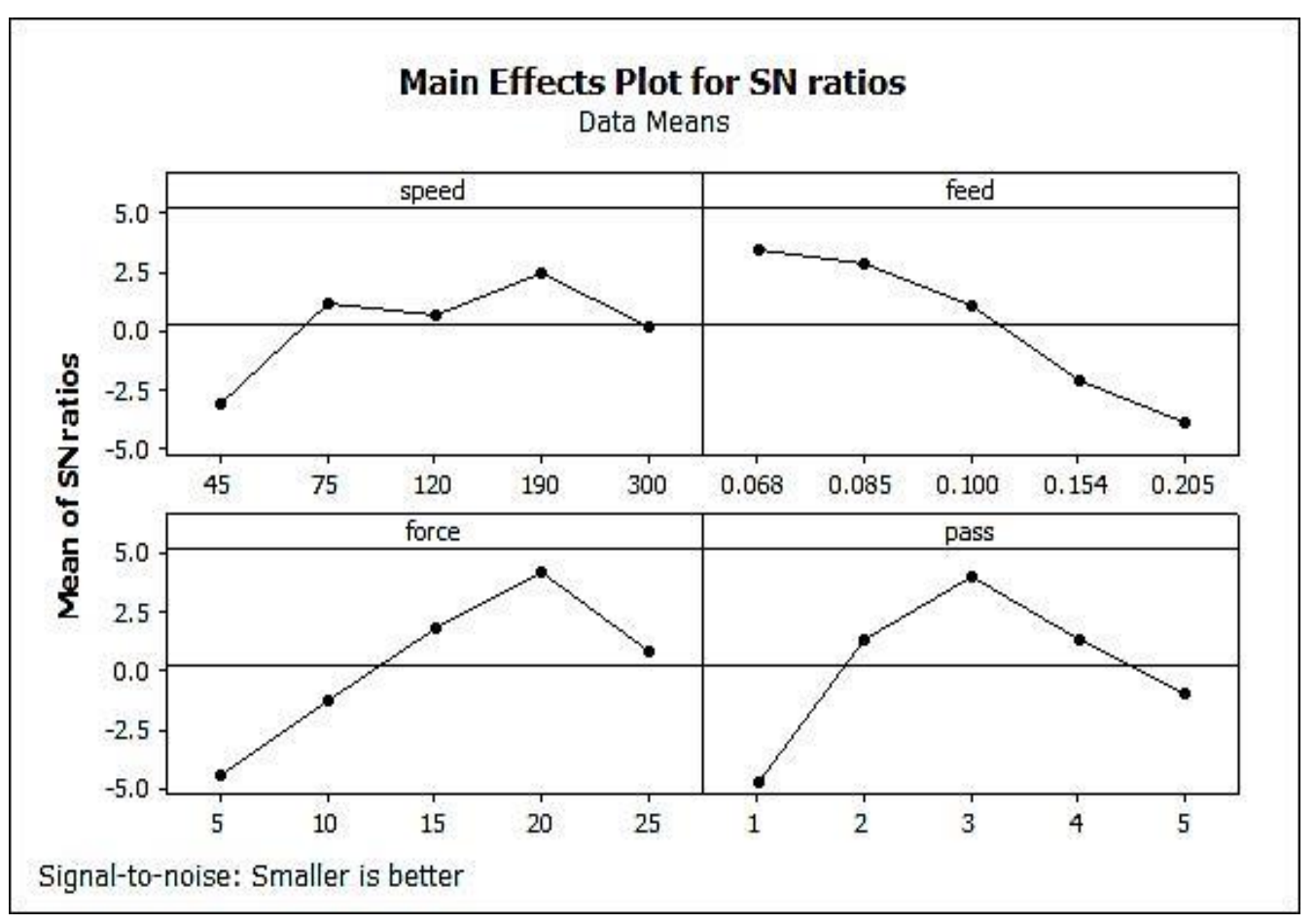

Figure 3. Main effect plot for $\mathrm{S} / \mathrm{N}$ ratios. 
Table 2. Surface roughness results.

\begin{tabular}{ccccc}
\hline $\begin{array}{c}\text { Speed } \\
(\mathrm{rpm})\end{array}$ & $\begin{array}{c}\text { Feed } \\
(\mathrm{mm} / \mathrm{rev})\end{array}$ & $\begin{array}{c}\text { Force } \\
(\mathrm{kgf})\end{array}$ & Number of passes & $\begin{array}{c}\text { Surface roughness } \\
(\mu \mathrm{m})\end{array}$ \\
\hline 45 & 0.068 & 5 & 1 & 2.95 \\
45 & 0.085 & 10 & 2 & 1.09 \\
45 & 0.1 & 15 & 3 & 0.56 \\
45 & 0.154 & 20 & 4 & 1.24 \\
45 & 0.205 & 25 & 5 & 2.7 \\
75 & 0.068 & 10 & 3 & 0.59 \\
75 & 0.085 & 15 & 4 & 0.63 \\
75 & 0.1 & 20 & 5 & 0.68 \\
75 & 0.154 & 25 & 1 & 1.29 \\
75 & 0.205 & 5 & 2 & 2.38 \\
120 & 0.068 & 15 & 5 & 0.58 \\
120 & 0.085 & 20 & 1 & 0.94 \\
120 & 0.1 & 25 & 2 & 0.74 \\
120 & 0.154 & 5 & 3 & 1.42 \\
120 & 0.205 & 10 & 4 & 1.25 \\
190 & 0.068 & 20 & 2 & 0.61 \\
190 & 0.085 & 25 & 3 & 0.38 \\
190 & 0.1 & 5 & 4 & 1.05 \\
190 & 0.154 & 10 & 5 & 1.34 \\
190 & 0.205 & 15 & 1 & 2.22 \\
300 & 0.068 & 25 & 4 & 0.65 \\
300 & 0.085 & 5 & 5 & 1.2 \\
300 & 0.1 & 10 & 1 & 1.87 \\
300 & 0.154 & 15 & 2 & 0.55 \\
300 & 0.205 & 20 & 3 & \\
\hline & & & & 5 \\
\hline
\end{tabular}

\section{Effect of Burnishing Force}

It can be observed from Figures 2 and 3 that the surface roughness decreased to a minimum value of $20 \mathrm{~N}$, and then started to increase with an increase in the burnishing force. As this force increased, the penetration depth of the ball into the metallic surface is increased, leading to a smoothing-out of the metallic surface. At a certain point, the surface began to show some deterioration caused by the flaking of the surface due to the high work hardening induced in the surface by the increase of plastic deformation as the burnishing force increased. When such deterioration of the surface occurs, the surface roughness of the specimen starts to increase.

\section{Effect of Number of Tool Passes}

From the curves in Figures 2 and 3, it can be seen that a reduction in surface roughness was achieved up to the first three passes in both figures; however, beyond this number of tool passes, the surface roughness started to increase. In each pass, the tool was applied with a constant burnishing force to the plastically deformed surface of the 
previous pass. Similar to the effect of burnishing force, after a particular number of passes, the surface layer becomes highly work-hardened, causing flaking to occur. This leads to the deterioration of the surface and to an increase in surface roughness. From the data, the optimum set of parameters was found: speed $=120 \mathrm{rpm}$, feed $=0.1$ $\mathrm{mm} / \mathrm{rev}$, force $=15 \mathrm{kgf}$, and No. of passes $=2$, as shown in Table 3 . The optimum value of surface roughness with the optimum set of parameters is given in Table 4 .

Table 3. Predicted optimum parameter values.

\begin{tabular}{cccc}
\hline $\begin{array}{c}\text { Speed } \\
(\mathrm{rpm})\end{array}$ & $\begin{array}{c}\text { Feed } \\
(\mathrm{mm} / \mathrm{rev})\end{array}$ & $\begin{array}{c}\text { Force } \\
(\mathrm{kgf})\end{array}$ & Number of passes \\
\hline 120 & 0.1 & 15 & 2 \\
\hline
\end{tabular}

Table 4. Surface roughness at predicted values.

\begin{tabular}{cc}
\hline Mean $(\mathrm{mm})$ & S/N Ratio \\
\hline 0.53 & 4.08635 \\
\hline
\end{tabular}

\section{CONCLUSIONS}

i) The surface roughness decreased with an increase in feed rate, burnishing speed, force, and number of tool passes to a certain limit, beyond which it then increased with each of the above-mentioned parameters.

ii) A reduction in burnishing speed resulted in a better surface finish of the specimen in the range of speed studied $(45-300 \mathrm{rpm})$. Feed rate of about 0.85 $\mathrm{mm} / \mathrm{rev}$ produced good surface characteristics.

iii) Burnishing force largely governs the degree of plastic deformation of the surface layers. There exists an optimum value of burnishing force for minimum roughness depending upon the chosen feed. In the present investigation, the range of optimum burnishing force is found to be 5-20 kgf.

iv) The optimal parameter combination for minimum surface roughness was obtained by analysis of the $\mathrm{S} / \mathrm{N}$ ratio. The optimal parameters for surface roughness were as follows: burnishing force, $15 \mathrm{kgf}$; No. of passes, 2; feed rate, $0.1 \mathrm{~mm} / \mathrm{rev}$; and speed, $120 \mathrm{rpm}$.

\section{REFERENCES}

Chen, C. H., \& Shiou, F. J. (2003). Determination of optimal ball-burnishing parameters for plastic injection moulding steel. The International Journal of Advanced Manufacturing Technology, 21(3), 177-185.

El-Axir, M. H., Othman, O. M., \& Abodiena, A. M. (2008a). Improvements in out-ofroundness of inner surfaces by internal ball burnishing process. Journal of Materials Processing Technology, 196, 120-128.

El-Axir, M. H., Othman, O. M., \& Abodiena, A. M. (2008b). Study on the inner surface finishing of aluminum alloy 2014 by ball burnishing process. Journal of Materials Processing Technology, 202, 435-442.

Hassan, A. M., \& Al-Bsharat, A. S. (1996a). Influence of burnishing process on surface roughness, hardness, and microstructure of some non-ferrous metals. Wear, 199: 1-8. 
Hassan, A. M., \& Al-Bsharat, A. S. (1996b). Improvements in some properties of nonferrous metals by the application of the ball burnishing process. Journal of Materials Processing Technology, 59, 250-256.

Hassan, A. M. (1997). The effect of ball and roller burnishing on the surface roughness and hardness of some non-ferrous metals. Journal of Materials Processing Technology, 72, 385-391.

Hassan, A. M., Al-Jalil, H. F., \& Ebied, A. A. (1998). Burnishing force and number of ball passes for the optimum surface finish of brass components. Journal of Materials Processing Technology, 83, 76-179.

Hassan, A. M., \& Maqableh, A. M. (2000). The effects of initial burnishing parameters on non-ferrous components. Journal of Materials Processing Technology, 102, 115-121.

Khan, M. A. R., Rahman, M. M., Kadirgama, K., Maleque, M. A., \& Ishak, M. (2011). Prediction of surface roughness of Ti-6Al-4V in electrical discharge machining: a regression model. Journal of Mechanical Engineering and Sciences, 1, 16-24.

Mohamed, N. M. Z. N., \& Khan, M. K. (2012). Decomposition of manufacturing processes: A review. International Journal of Automotive and Mechanical Engineering, 5, 545-560.

Najiha, M. S., Rahman, M. M., Yusoff, A. R., \& Kadirgama, K. (2012). Investigation of flow behavior in minimum quantity lubrication nozzle for end milling processes. International Journal of Automotive and Mechanical Engineering, 6, 768-776.

Sagbas, A., \& Kahrama, F. (2009). Determination of optimal ball burnishing parameters for surface hardness. Materials and Technology, 43(5), 271-274.

Singh, R. (2011). Process capability study of rapid casting solution for aluminum alloys using three-dimensional printing. International Journal of Automotive and Mechanical Engineering, 4: 398-405.

Singh, R. (2012). Comparison of polyjet printing and solution moulding as rapid plastic moulding solution. International Journal of Automotive and Mechanical Engineering, 6, 777-785. 